\title{
EDITORIAL: HOW WE TALK ABOUT WHAT WE HEAR
}

\author{
Juliet Fraser and Christopher Fox
}

Using words to describe music is a necessary but problematic task. As a means of introducing or explaining, it's a vital one, of course, but any attempt to recreate the listening experience is probably misguided, a Sisyphean effort. Which is good news for music: it can't be reduced; it can't be substituted. But we do want to talk about it, don't we, to share our experiences and insights, and for that we have to grapple with the inadequacies of words. Labels are particularly problematic; we may accept that they are dangerously but necessarily reductive as a shorthand, and that we all resent as missing-the-mark those that are applied to our own work, but how vigilant are we about the ones we bandy around?

The other day I [Juliet] was looking at a new score with a friend whose immediate response was to laugh, 'Ha! It's so German!' Actually, the composer wasn't German, and I was a bit surprised because this quality really hadn't struck me, and yet I suppose we both know what he meant. We use these labels to try to describe what we recognise in music, but nationality just doesn't seem an effective way of conceiving of music today, when the reach and availability of our sources and our creations is so unbound by geography. To think this way about the music of our time is hopeless, surely (and, if one goes along with the Hobsbawmian theory that the nation state is essentially a nineteenth-century (and European) blip, this model fails also to map onto the music of the past).

Of course, there are some composers whose music does sound 'British' (or should that be 'English' - pastoral, somehow? With flavours of Elgar, RVW or Britten, perhaps?), but in the music of most of my British composer friends I certainly don't sense a dominant style: one writes music that sounds rather French to me, another rather American (i.e. minimalist), one who's come over all Wandelweiser, one who loves to plunder the historical dressing-up box and don all sorts of national costumes. Isn't this the nub of it, that it's not so much about nationality as about influence?

Influence is a product of memory, history and, of course, geography too, but this issue demonstrates just how unpredictable the product can be. By accident rather than intention the articles in the pages that follow focus on just two geographical territories, Britain and Germany, but range across history, from the early days of the electronic music studio at Westdeutsche Rundfunk in the 1950s and '60s, through developments in electronic synthesis techniques in London in the 1970 s, to recent work by two very different composers, James Saunders and Jörg Widmann.

Some of the differences that emerge may seem to reinforce predictable national stereotypes: the WDR studio was run by a well- 
organised team, whereas Peter Zinovieffs EMS was a one-man-band. Others are more surprising: James Saunders's work has featured regularly at the major German new music festivals, whereas Widmann's devotion to the craft of instrumental writing and an obvious debt to the history of classical music are usually thought of as traditional virtues of British music.

In the midst of this is an article about Michael Tippett's Fourth Symphony, something of an exception in TEMPO's recent editorial history, which has favoured recent music by living composers. But Toby Young's article explores fascinatingly fresh ways of thinking about a work that has long been near the top of the list of Tippett's 'problem' works, mostly because the composer decided to incorporate the sound of human breathing into the music. A symphony framed by breathing is necessarily both universal and personal (although - to engineer a tenuous link to the WDR studio - Tippett does not follow Stockhausen's example in the last minutes of Hymnen and personalise the symphony by framing it with the sound of his own breathing).

Toby Young argues that this is music that not only transcends borders and cultures but also addresses the question of just what it is that works of music can accomplish, 'not only as musical representations of metaphysical issues, but as ontological doctrines in themselves, searching for answers through non-verbal investigation'. Yet these non-verbal answers seem to need verbal interpretation; whilst music may have a greater communicative power than words, the questions of identity and influence raised in this issue suggest that words may still be useful too. 